\title{
Determinants of Allergic Rhinitis in Young Children with Asthma
}

\author{
Lise Moussu ${ }^{1}$, Philippe Saint-Pierre ${ }^{2}$, Virginie Panayotopoulos ${ }^{1}$, Rémy Couderc ${ }^{3}$, Flore Amat ${ }^{1}$, \\ Jocelyne Just ${ }^{1 *}$
}

1 Allergology department, Centre de l'Asthme et des Allergies, Hôpital d'Enfants Armand-Trousseau (Assistance Publique Hôpitaux de Paris) - Université Pierre et Marie Curie, Paris, France, $\mathbf{2}$ Laboratoire de Statistiques Théoriques et Appliquées, Université Pierre et Marie Curie, Paris, France, 3 Service de Biochimie et Biologie Moléculaire, Hôpital d'Enfants Armand-Trousseau (Assistance Publique Hôpitaux de Paris), Paris, France

\begin{abstract}
Background: In the preschool period, allergic rhinitis (AR) is infrequent and thus under-diagnosed. However, recent works have highlighted the occurrence of AR in toddlers although the causes of AR in this young population remain unknown. The objective of this study was to identify determinants of AR in young children with asthma.

Methods: We carried out a case-control study of 227 children with active asthma and enrolled in the Trousseau Asthma Program. AR and other allergic diseases (asthma, food allergy and eczema) were diagnosed by medical doctors using standardized questionnaires. Parental history of AR and asthma, biological markers of atopy (total lgE, blood eosinophilia, allergic sensitization towards food and aeroallergens) and environmental parameters were also collected.

Results: Forty one of the children (18.1\%) had AR. By univariate logistic regression analysis, AR was mainly associated with peanut sensitization $(O R=6.75 ; p=0.002)$; food allergy $(O R=4.31 ; p=0.026)$; mold exposure $(O R=3.81 p<0.01)$ and parental history of $A R(O R=1.42 ; p=0.046)$. Due to the strong link between food allergy and peanut sensitization three models of multivariate logistic regression were performed and confirmed that AR is associated with peanut sensitization but also food allergy and mold exposure. A random forest analysis was also performed to explain AR. The results reinforced the logistic analysis that peanut sensitization and mold exposure were the principal determinants of AR.
\end{abstract}

Conclusions \& Clinical Relevance: These results stress the importance of investigating AR in young children with asthma to potentially diagnose a particularly severe allergic asthmatic phenotype. Moreover, these data evoke the hypothesis that peanut could be an aeroallergen.

Citation: Moussu L, Saint-Pierre P, Panayotopoulos V, Couderc R, Amat F, et al. (2014) Determinants of Allergic Rhinitis in Young Children with Asthma. PLoS ONE 9(5): e97236. doi:10.1371/journal.pone.0097236

Editor: Luo Zhang, Beijing Institiute of Otolaryngology, China

Received February 3, 2014; Accepted April 16, 2014; Published May 15, 2014

Copyright: (c) 2014 Moussu et al. This is an open-access article distributed under the terms of the Creative Commons Attribution License, which permits unrestricted use, distribution, and reproduction in any medium, provided the original author and source are credited.

Funding: The authors have no support or funding to report.

Competing Interests: The authors have declared that no competing interests exist.

*E-mail: jocelyne.just@trs.aphp.fr

\section{Introduction}

Allergic rhinitis (AR) is an atopic manifestation frequently associated with asthma. The prevalence of $\mathrm{AR}$ in children has been rising in many countries and is associated with a western lifestyle [1]. The Score for AR (SFAR) [2], which has been validated in the pediatric population after adding the idea of nasal itching [3], is a valuable diagnostic tool. The AR and its Impact on Asthma (ARIA)[4] classification further helps assess the severity of this pathology, as it takes into account the chronology of the symptoms and the discomfort they cause. In addition to causing other ear, nose and throat disorders [5] and harmful effects on quality of life [6], AR has been identified as a risk factor for asthma onset [7,8], severity and poor control [9]. The occurrence of AR in pre-school children is now widely accepted [10-12], but diagnosis has long been overlooked or questioned in early infancy. This is mainly explained by its similarity with infectious symptoms which are frequent in toddlers.
The « Pollution and Asthma Risk: an Infant Study » (PARIS) birth cohort, gave an estimated general prevalence of $\mathrm{AR}$ of around $9.1 \%$ in 18-month-old infants [13], but other studies give estimates ranging from 3 to $29 \%$, depending on how stringent the applied criteria were $[14,15]$. AR and asthma are two components of the chronic allergic respiratory syndrome, as they involve the same allergic immunological processes, fostering the concept of unity of the respiratory tract [16]. Nevertheless, because allergen sensitization of asthmatic infants seldom occurs, except for infants having an allergic phenotype [17], the mode of its association with $\mathrm{AR}$ is still unknown at this age of life.

Our study set out to identify determinants associated with AR in a case-control study performed in a cohort of young children with asthma. 


\section{Materials and Methods}

\section{Ethics}

Data were collected by standardized questionnaires and the medical examination was conducted by a physician after the parents gave their written informed consent. The Ile de France V ethics committee approved the protocol and this consent procedure.

\section{Population}

This case-control study gathered data from January to November 2011 and enrolled children who were part of the TAP (Trousseau Asthma Program). All the children had been referred to the center for recurrent wheezing by a primary care physician and joined the study consecutively.

Inclusion criteria for the study were: age younger than 30 months; persistent asthma (defined as a history of recurrent wheeze, more than three episodes of reversible bronchial obstruction documented within the previous 6 months) [18]; absence of other chronic obstructive pulmonary diseases (congenital or acquired), or exacerbation or acute respiratory illness within the 6 weeks preceding the explorations.

\section{Health outcomes}

General data were collected on the children's gender and age.

AR was diagnosed by a medical doctor supported by the SFAR criteria as defined by a score of 7 or more [3]. Based on these data, infants were allocated into two groups - one comprising children diagnosed with AR (the AR group) and the other comprising those without (the control group) - in a randomized manner and adjusted for age and gender.

Personal history of atopy (eczema) was mostly assessed by questions from the International Study of Asthma and Allergies in Childhood (ISAAC) [19]. Food allergy was defined by clinical symptoms of allergy after consumption of a food allergen and a positivity of specific IgE for the same allergen.

Moderate to severe asthma was determined according to the National Asthma Education and Prevention Program [20].

Finally, information about parental history (paternal and/or maternal) of $\mathrm{AR}$ and asthma were also gathered.

\section{Environmental factors}

Environmental factors were assessed by the questions applied in the PARIS birth cohort. We collected data about exclusive maternal breast-feeding beyond 3 months, exposure to passive smoking (defined by smokers at home smoking more than five cigarettes a day) and overcrowding (less than $9 \mathrm{~m}^{2}$ for each person living at home). Potential sources of biologic allergens were also evaluated: mold exposure (visible mold and moldy smell) and presence of visible cockroaches at home.

\section{Biological markers}

Biological markers of atopy were measured in peripheral blood. These included the multiple allergenic screening test Phadiatop infant and blood levels of specific IgE toward inhaled and food allergens (cow milk, egg, peanut, house dust mite, grass pollen, birch pollen, cat, dog and alternaria) for children testing positive. Children with two or more sensitizations to food and/or aeroallergens were considered to have polysensitization. Aeroallergen sensitization was defined as at least one sensitization to an inhaled allergen. Other inflammatory biological markers, such as total eosinophilia count and serum level of total $\mathrm{IgE}$, were measured too. Thresholds were used to define increased levels: increased blood eosinophilia was defined as a concentration $\geq 470$ eosinophils $/ \mathrm{mm}^{3}$, (cell count by automated Sysmex; France), increased total IgE as a concentration $\geq 45 \mathrm{kU} / \mathrm{L}$ [21] and positive specific $\operatorname{IgE} \geq 0.35 \mathrm{kU} / \mathrm{L}$ (ImmunoCAP; Uppsala, Sweden).

\section{Statistical analysis}

The chi-square test and Fisher's exact test were used to compare the distribution of each variable (clinical, environmental and environmental) between the control and the AR group. A logistic regression analysis [22] was used to examine the relationships between the binary outcome of interest (presence of AR) and multiple risk factors. Univariate and multivariate models, with and without interaction terms, were constructed to better understand the presence of AR. Spearman's correlation coefficient was computed to examine the association between variables. Risk factors associated with $\mathrm{AR}$ in the univariate analysis $(\mathrm{p}<0.2)$ were included in the multivariate analysis. The multivariate models were selected using the backward stepwise procedure.

A random forest analysis [23] was then applied to classify AR. This ensemble method uses a number of classification trees [24] to improve the classification compared to a single tree. In addition to the good predictive performance, random forests estimate the relevance (discriminating power) of each variable using importance measure (permutation-based mean decrease in accuracy). This non-linear approach provides an alternative to the logistic regression by providing another variables selection. Statistical analysis was performed with $\mathrm{R}$ version 2.12 .0 (http://www. r-project.org). The $\mathrm{R}$ package 'glm', 'Rpart' and 'randomForest' were used to perform the analysis.

\section{Results}

Forty-one of the 227 children seen in the TAP between January and November 2011 (18.1\%) had AR. Among the remaining 186 asthmatic children without AR, 88 were randomized and enrolled in the control group. The two groups were similar regarding age (17 [6-30] versus 16 [6-29] months in the AR and control group respectively) and gender (54\% boys in the AR group vs. $53 \%$ in the control group).

Risk factors for AR: descriptive analysis (Table 1, Table 2)

The AR group appeared to have - more features of allergy: food allergy $(p=0.042)$, allergic polysensitization $(p=0.030)$, especially due to peanut sensitization $(p=0.002)$ and greater exposure to mold $(p=0.030)$. Manifestations of food allergy were cutaneous (rash or facial edema) for seven of them and digestive (nausea or vomiting) for three. One child had both types of symptoms.

\section{Risk factors for AR: univariate logistic regression analysis (Table 3)}

In univariate logistic regression analysis, $\mathrm{AR}$ was found to be mainly associated with food allergy $(\mathrm{OR}=4.31 ; \mathrm{p}=0.026)$; peanut $(\mathrm{OR}=6.75 ; \mathrm{p}=0.002)$ and then with one environmental factor: mold exposure $(\mathrm{OR}=3.81 ; \mathrm{p}<0.01)$. Other risk factors were found to be: biological biomarkers identified by Phadiatop infant $(\mathrm{OR}=2.27 ; \mathrm{p}=0.046)$, more precisely polysensitization $(\mathrm{OR}=3.22 ; \mathrm{p}=0.019) ; \quad$ and egg sensitization $(\mathrm{OR}=2.56$; $\mathrm{p}=0.048)$; and finally a parental history of $\mathrm{AR}(\mathrm{OR}=1.42$; $\mathrm{p}=0.046)$. 
Table 1. Characteristic features of the entire population, the control group and the AR group.

\begin{tabular}{|c|c|c|c|c|}
\hline & Entire population $(n=129)$ & AR group $(n=41)$ & Control group $(n=88)$ & p-value* \\
\hline Eczema & $43(33.0)$ & $18(43.9)$ & $25(28.4)$ & 0.124 \\
\hline Food allergy & $11(8.5)$ & $7(17.1)$ & $4(4.5)$ & 0.042 \\
\hline Moderate to severe Asthma & $66(51.2)$ & $26(63.4)$ & $40(45.4)$ & 0.080 \\
\hline Parental history of Asthma & $3(2.3)$ & $0(0)$ & $3(3.4)$ & 0.770 \\
\hline Parental history of $A R$ & $12(9.3)$ & $6(14.6 \%)$ & $6(6.8)$ & 0.119 \\
\hline Eosinophilia $\left(\geq 470 / \mathrm{mm}^{3}\right)$ & $30(23.3)$ & $10(24.4)$ & $20(22.7)$ & 0.896 \\
\hline Elevated total $\lg \mathrm{E}(\geq 45 \mathrm{kU} / \mathrm{L})$ & $38(29.5)$ & $12(29.3)$ & $26(29.5)$ & 0.885 \\
\hline Phadiatop infant & $36(27.9)$ & $20(22.7)$ & $16(39.0)$ & 0.071 \\
\hline Polysensitization & $20(15.5)$ & $11(26.8)$ & $9(10.2)$ & 0.030 \\
\hline \multicolumn{5}{|c|}{ Sensitizations to food and aeroallergens ( $\geq 0.35 \mathrm{kU} / \mathrm{L}$ ) } \\
\hline Cow Milk & $24(18,6)$ & $11(26.8)$ & $13(14.8)$ & 0.163 \\
\hline Egg & $22(17.1)$ & $11(26.8)$ & $11(12.5)$ & 0.078 \\
\hline Peanut & $14(10.9)$ & $10(24.4)$ & $4(4.5)$ & 0.002 \\
\hline House dust mite & $10(7.8)$ & $4(9.8)$ & $6(6.8)$ & 0.820 \\
\hline Cat & $6(4.7)$ & $3(7.3)$ & $3(3.4)$ & 0.381 \\
\hline Dog & $1(0.8)$ & $1(2.4)$ & $1(1.1)$ & 0.999 \\
\hline Grass pollen & $2(1.6)$ & $1(2.4)$ & $1(1.1)$ & 0.536 \\
\hline Birch pollen & $1(0.8)$ & $1(2.4)$ & $0(0)$ & 0.318 \\
\hline Alternaria & $2(1.6)$ & $2(4.9)$ & $0(0)$ & 0.099 \\
\hline Any aeroallergen & $1(8.5)$ & $5(12.2)$ & $6(6.8)$ & 0.497 \\
\hline
\end{tabular}

Risk factors for AR: multivariate logistic regression analysis (Table 4)

In the multivariate analysis, model selection using an automatic stepwise procedure led to a model without interaction for the following variables: food allergy $\left(\mathrm{OR}_{\mathrm{a}}=3.96 ; \mathrm{p}=0.081\right)$, peanut sensitization $\left(\mathrm{OR}_{\mathrm{a}}=3.40 ; \mathrm{p}=0.075\right)$, mold exposure $\left(\mathrm{OR}_{\mathrm{a}}=3.20\right.$; $\mathrm{p}=0.013)$, familial history of $\mathrm{AR}\left(\mathrm{OR}_{\mathrm{a}}=1.45 ; \mathrm{p}=0.052\right)$ and moderate to severe asthma $\left(\mathrm{OR}_{\mathrm{a}}=1.24 ; \mathrm{p}=0.124\right)($ model 1$)$. A correlation study highlighted the association between food allergy and peanut sensitization $\left(\chi^{2}=11.23 ; \mathrm{p}<0.001\right)$. Such a correlation should be avoided as the two variables share common information. We thus constructed a model without peanut sensitization (Model 2) and a model without food allergy (Model 3) (Table 4). The OR associated with peanut sensitization or food allergy were found to be higher in these models. After adjustment, peanut sensitization, food allergy, parental history of AR and the presence of mold were found to increase the risk of AR.

\section{Risk factors for AR: random forest analysis}

The importance measure (permutation measure) obtained from the random forest analysis (Fig. 1) can be interpreted as a measure of discriminating power. These measures reinforced the previous results of peanut sensitization, mold exposure, moderate to severe asthma, parental history of AR, polysensitization and food allergy being determinants of $\mathrm{AR}$. The mold exposure and peanut sensitization were associated with the highest values and seems to be the most important variables to explain AR.

Table 2. Environmental characteristics of the entire population, the control group and the AR group.

\begin{tabular}{lllll}
\hline & & & & \\
\hline & Entire population $(\mathbf{n}=\mathbf{1 2 9})$ & AR group $(\mathbf{n}=\mathbf{4 1})$ & Control group $(\mathbf{n}=\mathbf{8 8})$ & p-value* \\
\hline Breastfeeding & $69(53.5)$ & $23(56.1)$ & $46(52.3)$ & 0.829 \\
Overcrowding & $12(9.3)$ & $2(4.9)$ & $10(11.4)$ & 0.336 \\
Mold exposure & $33(25.6)$ & $18(43.0)$ & $15(17.0)$ & 0.002 \\
Cockroaches & $9(7.0)$ & $3(7.3)$ & $6(6.8)$ & 0.999 \\
Passive smoking & $35(27.1)$ & $13(31.7)$ & $22(25)$ & 0.558 \\
\hline
\end{tabular}

All the values are expressed in absolute numbers and percentage in brackets *Chi-square test when conditions were respected or Fisher's exact test otherwise. Boldface values indicate statistical significance. Maternal breast-feeding beyond 3 months, Passive smoking (defined by smokers at home smoking more than 5 cigarettes a day). Overcrowding (less than $9 \mathrm{~m}^{2}$ for each person living at home). Mold exposure (visible mold and moldy smell) and cockroaches (visible cockroaches at home).

doi:10.1371/journal.pone.0097236.t002 
Table 3. Univariate logistic regression in the entire population $(n=129)$.

\begin{tabular}{|c|c|c|c|}
\hline & Odds ratio & $95 \% \mathrm{Cl}$ & p-value* \\
\hline Eczema & 1.97 & $0.91-4.27$ & 0.084 \\
\hline Food allergy & 4.32 & $1.19-15.73$ & 0.026 \\
\hline Moderate to severe Asthma & 1.40 & $0.94-2.10$ & 0.098 \\
\hline Parental history of AR & 1.42 & $1.01-2.02$ & 0.046 \\
\hline Mold exposure & 3.81 & $1.66-8.74$ & 0.002 \\
\hline Phadiatop infant & 2.27 & $1.01-5.07$ & 0.046 \\
\hline Polysensitization & 3.22 & $1.21-8.54$ & 0.019 \\
\hline Cow milk sensitization & 2.11 & $0.85-5.24$ & 0.105 \\
\hline Egg sensitization & 2.56 & $1.01-6.55$ & 0.048 \\
\hline Peanut sensitization & 6.77 & $1.98-23.19$ & 0.002 \\
\hline
\end{tabular}

*Wald test. Only p-value $<0.2$ are reported. Boldface values indicate statistical significance.

Food allergy was defined by clinical symptoms of allergy after consumption of a food allergen and a positivity of specific lgE for the same allergen. Moderate to severe asthma was determined according to the National Asthma Education and Prevention Program [20]. Mold exposure: visible mold and moldy smell. Allergen sensitization: specific $\lg \mathrm{E} \geq 0.35 \mathrm{kU} / \mathrm{L}$. Polysensitization: defined as two or more specific allergen sensitizations.

doi:10.1371/journal.pone.0097236.t003

\section{Discussion}

The main result of our study is that independent variables for $\mathrm{AR}$ in young asthmatic children are mainly peanut sensitization (linked to food allergy) and a moldy environment. Taking together all the results, in a less constant manner, an association was found between $\mathrm{AR}$ and moderate to severe asthma but also a parental history of $\mathrm{AR}$ and polysensitization.

\section{Sensitization to peanut results in a fivefold increase in the risk of $A R$}

In school age children, co-morbidities of allergic diseases such as $\mathrm{AR}$ and asthma occur more frequently in sensitized children (especially related to aeroallergen) $[25,26]$. The fact that biological evidence of atopy should lead to a suspicion of AR in infants has already been shown by Herr et al. [13] but without identifying a specific allergic sensitization.

In our study, peanut sensitization appeared to be an important determinant of AR in preschool children. Similarly, Kulig et al. highlighted the fact that sensitization to a food allergen is a risk factor for further sensitization to an aeroallergen even without clinical food allergy [27]. Moreover, a particular link between peanut sensitization and the severity of allergic disease (such as eczema) has recently been described in the LEAP (Learning Early About Peanut Allergy) study [28]. Finally, it has also recently been described that a certain amount of peanut present in home air could stimulate basophils under IgE immune response [29]. These results, along with ours, point up the possibility that inhaled peanut could be a specific trigger of $\mathrm{AR}$.

Moreover, we showed a significant link between food allergy and AR within the same toddler period. The relatively low importance of food allergy in random forest analysis was explained by the correlation with peanut sensitization [30]. This association between food allergy and allergic respiratory disease could simply reflect a particular severe allergic phenotype in young children with asthma, previously described by our team [17].

\section{Mold exposure an environmental determinants of AR}

Our findings identified indoor dampness and the resulting molds as important risk factors for $\mathrm{AR}$ in young children with asthma. This risk has also been pointed out by the ISAAC study in the 6 to 7 year-old age group [31]. A Finish cohort of children followed from age 1 to 7 years also linked mold to the de novo development of AR (OR = 1.96; CI 95\%: 1.29-2.99) and showed the increased risk to be dose-dependent [32]. There are certainly multiple mechanisms involved. Molds enhance direct sensitization

Table 4. Multivariate logistic regression in the entire population $(n=129)$.

\begin{tabular}{llll}
\hline & Model 1 OR (95\% CI) [p-value*] & Model 2 OR (95\% CI) [p-value*] & Model 3 OR (95\% CI) [p-value*] \\
\hline Food allergy & $3.96(0.84-18.57)[0.081]$ & $5.96(1.43-24.84)[0.014]$ & $5.02(1.38-18.25)[0.014]$ \\
Peanut sensitization & $3.40(0.86-13.07)[0.075]$ & & $2.86(1.18-6.94)[0.020]$ \\
Mold exposure & $3.20(1.28-7.97)[0.013]$ & $3.84(1.59-9.28)[0.003]$ & $1.41(0.97-2.05)[0.073]$ \\
Parental history of AR & $1.45(0.99-2.12)[0.052]$ & $1.46(1.01-2.13)[0.043]$ & $1.39(0.90-2.14)[0.136]$ \\
Moderate to severe asthma & $1.40(0.91-2.17)[0.124]$ & $1.41(0.92-2.16)[0.117]$ &
\end{tabular}

*Wald test. Risk factors associated with AR in the univariate analysis $(\mathrm{p}<0.2)$ are included in the multivariate analysis. Automatic backward stepwise procedure was used for model selection (Model 1). Due to the correlation between food allergy and peanut sensitization, one of these variables is removed from the selected model (Model 2 and Model 3). Boldface values indicate statistical significance.

Food allergy was defined by clinical symptoms of allergy after consumption of a food allergen and a positivity of specific lgE for the same allergen. Moderate to severe asthma was determined according to the National Asthma Education and Prevention Program [20]. Allergen sensitization: specific IgE $\geq 0.35 \mathrm{kU} / \mathrm{L}$. Mold exposure: visible mold and moldy smell. Cockroaches: visible cockroaches at home.

doi:10.1371/journal.pone.0097236.t004 
Mold exposure

Peanut sensitization

Moderate to severe asthma

Polysensitization

Parental history of AR

Phadiatop infante

Food allergy

Cow milk sensitization

Aeroallergen sensitization

Parental history of asthma

Egg sensitization

Eczema

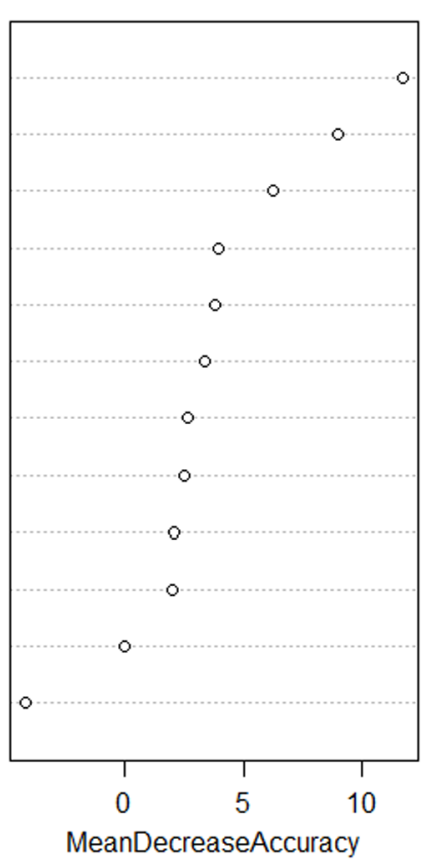

Figure 1. Importance measure (permutation-based mean decrease in accuracy) provided by the random forest analysis. Highest values of the importance measure are associated with a higher discriminating power.

doi:10.1371/journal.pone.0097236.g001

with specific $\mathrm{IgE}$ production. However, we believe that the detrimental exposure is more due to irritation than to allergic sensitization towards mold, especially in young children. In fact, it is well known that mold exposure promotes bacterial growth and the release of volatile organic compounds which enhance nonspecific inflammation especially in severe asthmatic children [33,34]. The increase of epithelial permeability could thus lead to sensitization to other aeroallergens [35].

\section{Influence of a parental history of AR}

Our study shows a link between the development of AR in early childhood and a parental history of AR. This result is in line with previous findings. The follow-up of the PARIS birth cohort estimated that a double parental history is associated with a twofold increased risk of the infant developing AR. In a study of children in Singapore, the risk of AR was 4.5 times higher (CI 95\%: 3.3-6.1) when both parents had AR [36]. This transmission of a precise phenotype has also been observed for atopic dermatitis and asthma. In the English ALSPAC cohort, a history of atopic dermatitis in both parents was associated with an OR of 2.72 (CI 95\%: 2.09-3.53) in children with atopic dermatitis [37]. Furthermore, the PARIS birth cohort showed that infants having an atopic asthma phenotype were more likely to have asthmatic parents [38]. The awareness of this phenotypic link could sensitize health professionals to the diagnosis of AR in asthmatic infants and improve their treatment and follow-up. In the same way, we recently found an association between mold exposure and AR present in a particularly severe allergic phenotype in young children with asthma [17].

\section{References}

1. Strachan D, Sibbald B, Weiland S, Ait-Khaled N, Anabwani G, et al. (1997) Worldwide variations in prevalence of symptoms of allergic rhinoconjunctivitis

\section{Severe asthma and its link with AR}

A link between AR and moderate to severe asthma as independent variables was found by random forest analysis with a borderline association in the three multivariate logistic regression models. It has been well reported in the literature that AR worsens the asthma prognosis [38], while intranasal treatment improves asthma outcomes [39]. Moreover, bronchial hyper-responsiveness is frequent in children with rhinitis especially in those with $A R$ [40]. Finally, AR is also more likely to persist during childhood than non AR [41].

\section{Polysensitization, another risk factor of AR}

Simpson et al. [42] showed that atopic sensitization is not a dichotomous trait in relation to allergic respiratory disease (especially asthma). They demonstrated that a particular phenotype associated with multiple early allergic sensitizations predicts not only the presence, but also the persistence and severity of childhood asthma.

On a clinical level, Schröder et al. [43] confirm this point of view, with a significant association between food allergy and risk of asthma in children from a family-based food allergy cohort. Moreover, in accordance with our study, they demonstrated that the association was stronger in children with multiple food allergies.

\section{Strengths and limitations of the study}

The main strength of this study lies in the use of precisely defined clinical parameters and biological markers. AR was assessed by medical doctors, supported by the SFAR criteria, which were more stringent than those used in previous studies [13]. Moreover, we had access (1) to a relatively large group of asthmatic toddlers with AR; (2) who shared close characteristics to toddlers with AR described in general population by Herr et al. [13]. Nevertheless, a limitation of our study is that we did not perform food challenges for diagnosing food allergies. Another limitation is that our questionnaire could have been more precise regarding environmental factors by using objective measurements. This fact may explain why our results did not show any link between AR and passive smoking, contrary to other authors $[7,44]$.

\section{Conclusions}

Our study reveals that in young children with asthma, AR could be a signal symptom of a severe allergic phenotype with a particular association with peanut sensitization. This data stresses the importance of thoroughly investigating AR so as not to miss potentially diagnosing a particular severe asthmatic phenotype. Finally our results raise the hypothesis that peanut could be considered as an inhaled allergen.

\section{Author Contributions}

Conceived and designed the experiments: JJ. Performed the experiments: LM PSP VP RC. Analyzed the data: LM PSP JJ. Contributed reagents/ materials/analysis tools: LM PSP VP JJ FA. Wrote the paper: LM JJ VP PSP. 
2. Annesi-Maesano I, Didier A, Klossek M, Chanal I, Moreau D, et al. (2002) The score for allergic rhinitis (SFAR): a simple and valid assessment method in population studies. Allergy 57: 107-114.

3. Braun-Fahrländer C, Wüthrich B, Gassner M, Grize L, Sennhauser FH, et al. (1997) Validation of a rhinitis symptom questionnaire (ISAAC core questions) in a population of Swiss school children visiting the school health services. SCARPOL-team. Swiss Study on Childhood Allergy and Respiratory Symptom with respect to Air Pollution and Cl. Pediatr Allergy Immunol 8: 75-82.

4. Bousquet J, Van Cauwenberge P, Khaltaev N (2001) Allergic rhinitis and its impact on asthma. J Allergy Clin Immunol 108: S147-334.

5. Hellings PW, Fokkens WJ (2006) Allergic rhinitis and its impact on otorhinolaryngology. Allergy 61: 656-664.

6. Silva CHM da, Silva TE da, Morales NMO, Fernandes KP, Pinto RMC (n.d.) Quality of life in children and adolescents with allergic rhinitis. Braz J Otorhinolaryngol 75: 642-649.

7. Wright AL, Holberg CJ, Martinez FD, Halonen M, Morgan W, et al. (1994) Epidemiology of physician-diagnosed allergic rhinitis in childhood. Pediatrics 94: 895-901.

8. Rochat MK, Illi S, Ege MJ, Lau S, Keil T, et al. (2010) Allergic rhinitis as a predictor for wheezing onset in school-aged children. J Allergy Clin Immunol 126: $1170-5 . e 2$

9. De Groot EP, Nijkamp A, Duiverman EJ, Brand PLP (2012) Allergic rhinitis is associated with poor asthma control in children with asthma. Thorax 67: 582587.

10. Peroni DG, Piacentini GL, Alfonsi L, Zerman L, Di Blasi P, et al. (2003) Rhinitis in pre-school children: prevalence, association with allergic diseases and risk factors. Clin Exp Allergy 33: 1349-1354

11. Wang WC, Lue KH, Sheu JN (n.d.) Allergic diseases in preschool children in Taichung City. Zhonghua Min Guo Xiao Er Ke Yi Xue Hui Za Zhi 39: 314 318.

12. Kulig M, Klettke U, Wahn V, Forster J, Bauer CP, et al. (2000) Development of seasonal allergic rhinitis during the first 7 years of life. J Allergy Clin Immunol 106: 832-839.

13. Herr M, Clarisse B, Nikasinovic L, Foucault C, Le Marec A-M, et al. (2011) Does allergic rhinitis exist in infancy? Findings from the PARIS birth cohort. Allergy 66: 214-221.

14. Ballardini N, Nilsson C, Nilsson M, Lilja G (2006) ImmunoCAP Phadiatop Infant - a new blood test for detecting IgE sensitisation in children at 2 years of age. Allergy 61: 337-343.

15. Martinez FD, Wright AL, Taussig LM, Holberg CJ, Halonen M, et al. (1995) Asthma and wheezing in the first six years of life. The Group Health Medical Associates. N Engl J Med 332: 133-138.

16. Togias A (2003) Rhinitis and asthma: evidence for respiratory system integration. J Allergy Clin Immunol 111: 1171-83.

17. Just J, Gouvis-Echraghi R, Couderc R, Guillemot-Lambert N, Saint-Pierre P (2012) Novel severe wheezy young children phenotypes: boys atopic multipletrigger and girls nonatopic uncontrolled wheeze. J Allergy Clin Immunol 130: $103-10$.

18. Tabachnik E, Levison H (1981) Postgraduate course presentation. Infantile bronchial asthma. J Allergy Clin Immunol 67: 339-347.

19. Asher MI, Keil U, Anderson HR, Beasley R, Crane J, et al. (1995) International Study of Asthma and Allergies in Childhood (ISAAC): rationale and methods. Eur Respir J 8: 483-491.

20. NAEPP 2007 Guidelines. Available: http://www.nhlbi.nih.gov/guidelines/ asthma/asthsumm.pdf. Accessed 27 April 2014.

21. Just J, Nicoloyanis N, Chauvin M, Pribil C, Grimfeld A, et al. (2008) Lack of eosinophilia can predict remission in wheezy infants? Clin Exp Allergy 38: 767773.

22. Hosmer D, Lemeshow S (2004) Applied Logistic Regression. Wiley.

23. Breiman L (2001) Random forests. Mach Learn 45:5-32.
24. Breiman L, Olshen RA, Stone CJ (1984) Classification and regression trees. Wadsworth \& Brooks/Cole., editor Advanced Books and Software.

25. Arshad SH, Tariq SM, Matthews S, Hakim E (2001) Sensitization to common allergens and its association with allergic disorders at age 4 years: a whole population birth cohort study. Pediatrics 108: E33.

26. Kjaer HF, Eller E, Høst A, Andersen KE, Bindslev-Jensen C (2008) The prevalence of allergic diseases in an unselected group of 6-year-old children. The DARC birth cohort study. Pediatr Allergy Immunol 19: 737-745.

27. Kulig M, Bergmann R, Tacke U, Wahn U, Guggenmoos-Holzmann I (1998) Long-lasting sensitization to food during the first two years precedes allergic airway disease. The MAS Study Group, Germany. Pediatr Allergy Immunol 9: 61-67.

28. Du Toit G, Roberts G, Sayre PH, Plaut M, Bahnson HT, et al. (2013) Identifying infants at high risk of peanut allergy: the Learning Early About Peanut Allergy (LEAP) screening study. J Allergy Clin Immunol 131: 135-43.

29. Brough HA, Santos AF, Makinson K, Penagos M, Stephens AC, et al. (2013) Peanut protein in household dust is related to household peanut consumption and is biologically active. J Allergy Clin Immunol 132: 630-638.

30. Tolosi L, Lengauer T (2011) Classification with correlated features: unreliability of feature ranking and solutions. Bioinformatics 27: 1986-1994.

31. Zacharasiewicz A, Zidek T, Haidinger G, Waldhör T, Vutuc C, et al. (2000) Symptoms suggestive of atopic rhinitis in children aged 6-9 years and the indoor environment. Allergy 55: 945-950.

32. Jaakkola JJK, Hwang B-F, Jaakkola MS (2010) Home dampness and molds as determinants of allergic rhinitis in childhood: a 6 -year, population-based cohort study. Am J Epidemiol 172: 451-459.

33. Mudarri D, Fisk WJ (2007) Public health and economic impact of dampness and mold. Indoor Air 17: 226-235.

34. O'Sullivan MM, Brandfield J, Hoskote SS, Segal SN, Chug L, et al. (2012) Environmental improvements brought by the legal interventions in the homes of poorly controlled inner-city adult asthmatic patients: a proof-of-concept study. J Asthma 49: 911-917.

35. Husman T (1996) Health effects of indoor-air microorganisms. Scand J Work Environ Health 22: 5-13

36. Lee JT, Lam ZCM, Lee WT, Kuo LCT, Jayant V, et al. (2004) Familial risk of allergic rhinitis and atopic dermatitis among Chinese families in Singapore. Ann Acad Med Singapore 33: 71-74.

37. Wadonda-Kabondo N, Sterne JAC, Golding J, Kennedy CTC, Archer CB, et al. (2004) Association of parental eczema, hayfever, and asthma with atopic dermatitis in infancy: birth cohort study. Arch Dis Child 89: 917-921.

38. Clarisse B, Demattei C, Nikasinovic L, Just J, Daures J-P, et al. (2009) Bronchial obstructive phenotypes in the first year of life among Paris birth cohort infants. Pediatr Allergy Immunol 20: 126-133.

39. Lohia S, Schlosser RJ, Soler ZM (2013) Impact of intranasal corticosteroids on asthma outcomes in allergic rhinitis: a meta-analysis. Allergy 68: 569-579.

40. Kim S-W, Han DH, Lee S-J, Lee CH, Rhee C-S (n.d.) Bronchial hyperresponsiveness in pediatric rhinitis patients: the difference between allergic and nonallergic rhinitis. Am J Rhinol Allergy 27: e63-8.

41. Westman M, Stjärne P, Asarnoj A, Kull I, van Hage M, et al. (2012) Natural course and comorbidities of allergic and nonallergic rhinitis in children. J Allergy Clin Immunol 129: 403-408.

42. Simpson A, Tan VYF, Winn J, Svensén M, Bishop CM, et al. (2010) Beyond atopy: multiple patterns of sensitization in relation to asthma in a birth cohort study. Am J Respir Crit Care Med 181: 1200-1206.

43. Schroeder A, Kumar R, Pongracic JA, Sullivan CL, Caruso DM, et al. (2009) Food allergy is associated with an increased risk of asthma. Clin Exp Allergy 39: 261-270.

44. Biagini JM, LeMasters GK, Ryan PH, Levin L, Reponen T, et al. (2006) Environmental risk factors of rhinitis in early infancy. Pediatr Allergy Immunol 17: $278-284$. 